\title{
Diuretic Activity of Methanol Extracts of Rubus idaeus L.
}

\author{
Ying Zhang \\ School of Life and Environmental Sciences, University of Tsukuba \\ Tsukuba 305-8572, Japan
}

Tel: 81-29-853-6972Ｅ-mail: zzwater000@gmail.com

Zhenya Zhang (Corresponding author)

School of Life and Environmental Sciences, University of Tsukuba

Tsukuba 305-8572, Japan

Tel: 81-29-853-4712Ｅ-mail: tyou6688@sakura.cc.tsukuba.ac.jp

Yingnan Yang

School of Life and Environmental Sciences, University of Tsukuba

Tsukuba 305-8572, Japan

Tel: 81-29-853-6972Ｅ-mail: yo.innan.fu@u.tsukuba.ac.jp

\section{Yuepeng Wang}

School of Life and Environmental Sciences, University of Tsukuba

Tsukuba 305-8572, Japan

Tel: 81-29-853-6972Ｅ-mail: ouetsuhou@hotmail.com

Xiaoyan $\mathrm{Zu}$

School of Life and Environmental Sciences, University of Tsukuba

Tsukuba 305-8572, Japan

Tel: 81-29-853-6972Ｅ-mail: xiaoyanzu@gmail.com

Di Guan

School of Life and Environmental Sciences, University of Tsukuba

Tsukuba 305-8572, Japan

Tel: 81-29-853-6972Ｅ-mail: kanteki09@hotmail.com

Received: November 25, 2010 Accepted: December 12, 2010 doi:10.5539/ijb.v3n2p75

\begin{abstract}
The purpose of this article is to evaluate the diuretic potential of Rubus idaeus $L$. fruits. By measuring the urine volume of experimental animals, we find that methanol extract of Rubus idaeus L. fruits significantly increased the urine volume of experimental animals suggesting its diuretic effect. This is the first formal report on the diuretic activity of Rubus idaeus L. fruits. Moreover, four fractions isolated from the methanol extract were further studied and the results showed that ethyl acetate fraction (RIEA) has a direct relationship with the diuretic activity of Rubus idaeus L. fruits. The urinary electrolyte patterns of experimental animals were also analyzed, we find that Rubus idaeus $L$. fruits have an effect on the conservation of potassium, which is an interesting property in a phyto-diuretic.
\end{abstract}


Keywords: Rubus idaeus L., Diuretic effect, Methanol extract, ethyl acetate fraction

\section{Introduction}

Raspberry, Rubus idaeus L., is a plant belonging to the Rosaceae family, genus Rubus. The geographical distribution of Rubus idaeus $L$. covers a wide range from Europe to northern Asia and most temperate areas. As a well known fruit crop, raspberry fruits were used not only for nutritional purpose, in many countries, it is also used as a folk medicine to treat wounds, colic pain and some other disease like diarrhea and renal disease (Bluenthal, M., 1998; D’Amelio, F.S., 1999 and Ryan, T. et al., 2001).

During the past two decades, many researchers have studied biological effects of Rubus idaeus L. components. Parsons, M. et al. (1999) and Simpson, M. et al. (2001) examined the safety and efficacy of Rubus idaeus L. leaf products. Their results suggest that raspberry leaf may have an effect on shortening the labor process and reduce the need for medical intervention for mothers during their pregnancy. See also Whitehouse, B. (1941), Parsons, M. (2000) and Patel, A.V. (2003). According to Juranic, Z. et al., (2005), water extract of Rubus idaeus L. seeds possess the potential for anti-proliferative action against human colon carcinoma cells in vitro. More discussions about raspberry seeds can also be found in Oomah, B.D et al. (2000) and the literatures therein. For raspberry fruits, it has been reported that high levels of phenolic and anthocyanin compounds with potential health benefits is contained (Daniel et al., 1989; Maas et al., 1991; Heinonen et al., 1998; Kahkonen et al., 2001; Mullen et al., 2002), suggesting the significant health benefits of Rubus idaeus L. fruits. Heinonen et al., (1998) also showed that raspberry fruit inhibit low-density lipoprotein and liposome oxidation. Recent studies have confirmed that raspberry fruits have the activities of anti-oxidant, anti-proliferative, anti-obese, antibacterial and anti-inflammatory (Ryan, T et al., 2001; Chanjirakul, K. 2006; Camille S. Bowen-Forbes, et al., 2009; Ji-Hyun Jeong et al., 2010).

In Chinese traditional medical practice, raspberry fruits are known as a cure for renal diseases. In some countries, people also think that raspberry has mild diuretic effect and could increase urination. According to Heinonen et al. (1998), Kahkonen et al. (2001) and Mikko J. Anttonen, high level of phenolic is contained in the Rubus idaeus $L$. fruits, and some of the phenolic components have diuretic activity (Galati, E.M. et al., 1996). The folk-medicine use of raspberry fruits and the researches mentioned above seem to provide a possibility to identify the diuretic activity of raspberry fruits. However, to the best of our knowledge, no formal research has been involved in examining its diuretic effect. The main object of this paper is then to evaluate the diuretic activity of raspberry, so as to enhance our understanding about this widely used fruit crop.

\section{Materials and methods}

\subsection{Plant materials and preparation of the crude extracts}

Three kinds of Rubus idaeus L. fruits were used in our experiments: frozen cultivar from Chile (T), immature cultivar named FuPenZi (F), which is also known as a Traditional Chinese Medicine and mature wild Rubus idaeus $L$. fruits (R). The first two kinds of Rubus idaeus $L$. fruits were obtained from local market, and the wild Rubus idaeus L. fruits were collected from LiaoNing Province, China by local practitioners in 2008, identified and authenticated as Rubus idaeus L. by Professor Jincai Lu (Colledge of Traditional Chinese Meteria Medica, ShenYang Pharmaceutical University, China). A voucher speciman (No. 20080920RI) was preserved at the Herbarium of Medicinal Plant, ShenYang Pharmaceutical University, China.

All the experimental plants were air-dried in an oven at a temperature of $40^{\circ} \mathrm{C} \pm 2^{\circ} \mathrm{C}$ until constant weights were obtained. The dried fruits were ground to powder in an electric grinder and then were boiled in distilled water and $99.5 \%$ methanol $(\mathrm{m} / \mathrm{v}=1 / 20)$ for $2 \mathrm{~h}$ respectively. The decoction obtained were centrifuged and filtered through Whatman no.4 filter paper. This procedure was repeated three times and the combined filtrates were evaporated on rotary evaporator to dryness under reduced pressure. All the six kinds of Rubus idaeus L. extracts were stored at $-20^{\circ} \mathrm{C}$ and prepared daily just before use.

\subsection{Preparation of the fractions}

The crude methanol extracts of mature wide Rubus idaeus $L$. fruits $(\mathrm{R})$ were suspended in water and subjected to solvent-solvent partitioning using petroleum ether, ethyl acetate and n-buthanol to produce petroleum ether fraction (RIPE), ethyl acetate fraction (RIEA), butanol fraction (RIBuOH) and water fraction (RW), with an increase in the polarite.

\subsection{Experimental animals}

Male rats weighing (250 300g), obtained from the Animal Experimental Center, Tsukuba University, were used for our experiments. The animals were housed in a temperature and light-controlled room $\left(25^{\circ} \mathrm{C} ; 14 \mathrm{~h} / 10 \mathrm{~h}\right.$ 
light/dark cycle) with free access to food and drinking water. Before our experiments, the animals were acclimatized in the laboratory for a period of at least one week.

All rat experiments were carried out in a human manner after receiving approval from Institutional Animal Experiment Committee of the Tsukuba University (Japan), and in accordance with the regulations for animal experiments and fundamental guidelines under the jurisdiction of the Japanese Ministry of Education, Culture, Sports, Science and Technology.

\subsection{Drug}

Hydrochlorothiazide (HCTZ; obtained from Wako Pure Chemical Industries) was used as a reference diuretic drug.

\subsection{Diuretic activity}

\subsubsection{Diuretic activity of crude extracts}

Diuretic activity was determined following the methods of Kawashima et al. (1985), with minor modification. For the methanol and hot water extract, 48 rats were fasted for $18 \mathrm{~h}$ with free access to drinking water, and then orally administered with $30 \mathrm{ml} / \mathrm{kg}$ of bicarbonate saline solution (containing $110 \mathrm{mM} \mathrm{NaCl}$ and $30 \mathrm{mM}$ $\mathrm{NaHCO} 3)$ before the experiment. 30 minutes later, they were divided into 8 groups $(\mathrm{n}=6)$. Control group was given $10 \mathrm{ml} / \mathrm{kg} \mathrm{BW}$ (body weight) of distilled water. The positive control animals received hydrochlorothiazide at $10 \mathrm{mg} / \mathrm{kg} \mathrm{BW}$ in distilled water. Treatment groups were given plants extracts at a dose of $2 \mathrm{~g} \mathrm{dw}$ (dry weight of fruits before extract)/kg BW for each rat. Animals were then put into metabolic cages individually with evacuation of the bladder. The cages were equipped with bottles for drinking water ad libitum.

\subsubsection{Diuretic activity of four fractions}

Diuretic activities of four fractions were determined following the same method as introduced above. 36 rats were used in this step. Treatment groups were given fractions at a dose of $200 \mathrm{mg} / \mathrm{kg} \mathrm{BW}$ for each rat.

\subsubsection{Electrolyte concentrations}

Urine samples were collected and the urine volume was measured hourly for $4 \mathrm{hs}$ and then assayed for $\mathrm{Na}^{+}$and $\mathrm{K}^{+}$concentrations (Mukherjee et al., 1996, Murugesan et al., 2000). $\mathrm{Na}^{+}$and $\mathrm{K}^{+}$concentrations were measured using ICP Atomic Emission Spectrometer (ICPS-8100, SHIMAZU).

\subsection{Statistical analysis}

Results are expressed as the mean values \pm SEM (Standard Error of Mean). The statistical evaluation was carried out by analysis of variance (ANOVA) followed by Student's t-test for multiple comparisons. When compared with control group, P-values less than 0.05 were considered statistically significant.

\section{Results}

\subsection{Urine volume produced by crude extracts}

Table 1 exhibits the volume of urine collected every hour from the animals treated with Distilled water, diuretic drug hydrochlorothiazide, and 6 kinds of Rubus idaeus L. extracts. Positive control group treated with hydrochlorothiazide showed the highest output of urine during the first hour, as well as the maximum of total urine volume. It should also be noted that for the positive control group, the diuretic action was 1.90, the highest value observed when compared with the control group.

Interestingly, as can be seen from Table 1, Rubus idaeus L. methanol extract (RM) with dose $2 \mathrm{mg} / \mathrm{kg}$ BW produced maximum output of urine volume during the second, the third and the forth hour, with $0.58,0.69$ and $0.54 \mathrm{ml} / 100 \mathrm{~g} \mathrm{BW}$, respectively. The total urine volume of animals treated by RM is also high with $2.32 \pm 0.12$ $\mathrm{ml} / 100 \mathrm{~g} \mathrm{BW}$ (mean \pm S.E.M). Compared with the control group, the increase of urine volume becomes significant from the third hour, suggesting diuretic activities of Rubus idaeus L. methanol extract on the experimental animals. The diuretic action of RM was 1.69 , which is also the highest value of those observed from all the Rubus idaeus $L$. extracts.

\subsection{Urine volume produced by four fractions}

Figure 1 exhibits the volume of urine collected every hour for $4 \mathrm{hs}$ from the animals tested with HCTZ and four kinds of methanol extract fractions: RIPE, RIEA, RIBuOH and RIW. As can be seen from Figure 1, HCTZ produced urine volume of about $3.4 \mathrm{ml} / 100 \mathrm{~kg} \mathrm{BW}$, which is a value larger than those produced by the four fractions. RIEA fraction caused total amount of urine volume of about $2.8 \mathrm{ml} / 100 \mathrm{~kg} \mathrm{BW}$. It is a value less than that produced by HCTZ, meanwhile, it is the maximum among the four fractions. Comparing with the control 
group, the increase of urine volume produced by RIEA fraction is significant during the first and the second hour, implicating that the Methanol extract RIEA fraction exhibited diuretic activities in the experimental animals.

\subsection{Urinary electrolytes}

In what follows, we focus on the urinary electrolytes to see on which parts Rubus idaeus L. components show their diuretic activities. In our experiments, the excretion of urinary sodium and potassium were measured every hour from the collected urine of the tested animals, and data were shown in Table 2.

For the positive control group treated with hydrochlorothiazide, the amount of sodium was markedly increased almost every hour throughout the experiment. During the first hour, compared with the control group, HCTZ produced $66 \%$ more sodium excretion. From the second hour, the sodium excretion produced by HCTZ becomes significantly larger than those of the control group. The sodium excretion of positive control group observed during the forth hour is $139.42 \pm 18.57 \mathrm{mmol} / \mathrm{L}$, a little bit smaller than that of the control group with an observed value of $143.32 \pm 18.41 \mathrm{mmol} / \mathrm{L}$. In contrast, the sodium excretion caused by RIEA was relatively smaller than that produced by HCTZ. During the first and the third hour, sodium excretions observed from the animals treated with RIEA were $87.12 \mathrm{mmol} / \mathrm{L}$ and $128.84 \pm 13.66 \mathrm{mmol} / \mathrm{L}$ respectively, significantly larger than those of control group. However, during the second and the forth hour, the sodium excretion caused by RIEA remained at a level of $110 \mathrm{mmol} / \mathrm{L}$.

It is well known that HCTZ can cause the increase of both sodium and potassium excretions in the urine of experimental animals. Throughout the experiments, potassium excretion in the urine of positive control group was significantly larger than that of the control group, which agrees with some results in the previous studies. However, different from HCTZ, RIEA caused a decrease of potassium excretion in our experiment. As can be seen from Table 2, during the first hour, the potassium excretion produced by RIEA was $33.34 \pm 5.86 \mathrm{mmol} / \mathrm{L}$, while that of the control group was $56.88 \pm 5.93 \mathrm{mmol} / \mathrm{L}$. In the following hours, the observed value of potassium excretion were $61.11 \pm 9.10 \mathrm{mmol} / \mathrm{L}, 51.80 \pm 9.37 \mathrm{mmol} / \mathrm{L}$ and $72.58 \pm 2.09 \mathrm{mmol} / \mathrm{L}$, all of these values were smaller than those observed from the control group. This is a very interesting found from our experiment, which also suggests that $\mathrm{HCTZ}$ and Rubus idaeus $L$. fruits show their diuretic activity in distinct ways.

\section{Discussions and conclusions}

The purpose of our research is to evaluate the diuretic activity of Rubus idaeus $L$. fruits. For doing so, three kinds of Rubus idaeus L. fruits were used in our experiments. Including Rubus idaeus $L$. artificially cultivated in Chile, immature Rubus idaeus $L$. fruits artificially cultivated in China and wild Rubus idaeus L. fruits collected from LiaoNing Province, China. According to Cetin Cekic et al., 2009 and Shiow Y. Wang et al., 2009, chemical properties of Rubus idaeus $L$. fruits might be different between the wild species and those cultivated, and maturity could also show an influence in the chemical properties of Rubus idaeus L. fruits. Our results showed that neither of the two kinds of cultivars ( $\mathrm{T}$ or $\mathrm{F}$ ) caused a significant increase in total urine volume. In contrast, wild species collected from China showed significant diuretic effect on experimental rats, implicating that wild Rubus idaeus $L$. fruits might contain more diuretic active ingredients than those cultivars.

Two kinds of solvent systems, hot-water and methanol 99.5\%, were used to extract the active ingredients from Rubus idaeus $L$. fruits. Compared with the control group, no significant increase in the urine volume of was observed in the group treated with hot-water extracts. One possible reason considered here is that the active ingredient in Rubus idaeus $L$. fruits is not water-soluble. However, when the Rubus idaeus L. fruits powder in the hot-water were increased from $2 \mathrm{~g}$ to $5 \mathrm{~g}$, RW produced a significant increase in the urine volume (data is not shown). Hence it seems more natural to think that the Rubus idaeus $L$. water extract has a dose-dependent diuretic effect. Nevertheless, we failed to obtain more persuasive evidence throughout the experiment.

In order to specify the chemical compositions that contributed to the diuretic effect of Rubus idaeus $L$. fruits, we use three solvent systems to isolate four fractions from methanol extract. Results showed that RIEA fraction produced the largest amount of urine excretion. Such a diuretic effect is significant when compared to the control group. Based on such a result, we consider that RIEA fraction has a direct relationship with the diuretic effect of Rubus idaeus L. fruits.

The sodium excretions in the urine of animals tested with methanol extract RIEA fraction were higher than that of the control group during the first and the third hour. In contrast, interestingly, a marked reduction in potassium excretion by RIEA fraction was also observed throughout the experiment. For the RIEA fraction, the $\mathrm{Na} / \mathrm{K}$ ratio reached values of $2.6(1 \mathrm{st} \mathrm{h}), 1.8(2 \mathrm{nd} \mathrm{h}), 2.5(3 \mathrm{rd} \mathrm{h})$ and $1.5(4 \mathrm{th} \mathrm{h})$, much higher than that observed from the control group. And this value is also far higher than that produced by HCTZ. It is so because as the sodium excretion shows a scale-up trend as time pass by, the potassium excretion by the methanol extract, however, 
extends in the opposite direction. For many drugs and plants having diuretic effect, the increase of excretion for potassium and sodium are usually observed simultaneously. In this case, although both the HCTZ and the methanol extract showed a notable diuretic effect, the different results obtained on electrolytic excretion produced by HCTZ and methanol extract suggest a difference in their comparative diuretic profiles.

It is well known that hydrochlorothiazide acts on the distal convoluted tubule and inhibits the sodium-chloride symporter leading to the retention of water in the urine (Sripanidkulchai et al., 2001) as water normally follows penetrating solutes. In our experiments, both HCTZ and RIEA fraction promoted water excretion from experimental rats. However, as has been mentioned before, they did so in distinct ways. Considering the electrolyte pattern observed from the urine of experimental rats tested with RIEA fraction, we conclude that the possible diuretic mechanism of may be that some chemical compositions contained in the RIEA fraction act on distal parts of the nephron (Morrison RT. 1997, Antes LM. 1998, Giebisch G. 2007), where they either inactivate an aldosterone-sensitive sodium channel in the collecting duct to decrease reabsorption of sodium and water or inhibit the ATP-dependent $\mathrm{Na}^{+} / \mathrm{K}^{+}$pump. The increased sodium and water excretion activity also provides strong basis for its anti-hypertensive action.

In conclusion, based on the results obtained from our experiments, we conclude that Rubus idaeus L. fruits have diuretic effect in urine volume on experimental rats. Moreover, the presented study provides an evidence for explaining the use of Rubus idaeus $L$. as a diuretic agent in Traditional Chinese Medicine. The notable diuretic effect observed from the methanol extract as well as having an interesting effect on the conservation of potassium is an interesting property in a phyto-diuretic.

\section{References}

Antes, L.M. \& Fernandez, P.C. (1998). Principles of diuretic therapy. Dis Mon, 44(6), 254-268.

Blumenthal, M., (Ed) (1998). The Complete Commission German E Monographs. American Botanical Council, Texas, USA.

Camille, S., Bowen-Forbes, Yanjun, Z. \& Muralledharan, G. (2010). Anthocyanin content, antioxidant, anti-inflammatory and anticancer properties of blackberry and raspberry fruits. Journal of Food Composition and Analysis, 23, 554-560.

Cetin Cekic \& Mustafa Ozgen. (2010). Comparison of antioxidant capacity and phyto-chemical properties of wild and cultivated red raspberries (Rubus idaeus L.). Journal of Food Composition and Analysis, 23(6), 540-544.

Chanjirakul, K., Wang, C.Y., Wang, S.Y. \& Siriphanich, J. (2006). Effect of natural volatile compounds on antioxidant capacity and antioxidant enzymes in raspberries. Postharvest Biology and Technology 40:106-115.

D'Amelio, F.S. (1999). Botanicals - A Phytocosmetic Desk Reference. CRC Press, Boca Raton, FI.

Daniel, E.M., Krubnick, AS, Heur, Y.H., Blinzler, JA, Nims, R.W. \& Stoner, G.D. (1989). Extraction, stability, and quantitation of ellagic acid in various fruits and nuts. J Food Comp Anal, 2, 338-349.

Galati, E.M., Tripodo, M.M., Trovato, A., Miceli, N. \& Monforte, M.T. (2002). Biological effect of Opuntia ficus indica (L.) Mill. (Cactaceae) waste matter. Note I: diuretic activity. J Ethnopharmacol, 79(1), 17-21.

Giebisch, G., Krapf, R. \& Wagner, C. (2007). Renal and extrarenal regulation of potassium. Kidney Int 72, 397-410.

Heinonen, I.M., Meyer, A.S. \& Frankel, E.N. (1998). Antioxidant activity of berry phenolics on human low-density lipoprotein and liposome oxidation. J. Agric. Food Chem, 46, 4107-4112.

Ji-Hyun Jeong, Hana Jung, Sae-Rom Lee, Hee-Jae Lee, Keum Taek Hwang, Tae-Young Kim. (2010). Anti-oxidant, anti-proliferative and anti-inflammatory activities of the extracts from black raspberry fruits and wine. Food Chemistr, 123, 338-344.

Juranic, Z., Zizak, Z., Tasic, S., Petrovic, S., Nidzovic, S., Leposavic, A. \& Stanojkovic, T. (2005). Antiproliferative action of water extracts of seeds or pulp of five different raspberry cultivars. Food Chemistry, 93(1), 39-45.

Kahkonen M.P., Hopia A.I. \& Heinonen M. (2001). Berry phenolics and their antioxidant activity. J. Agric. Food Chem, 49, 4076-4082.

Kawashima, K., Miwa, Y. \& Kimura, M. (1985). Diuretic action of paeonol. Planta Medica, 50, 187-189. 
Maas, J.L., Galletta, G.J. \& Stoner, G.D. (1991a). Ellagic acid, an anticarcinogen in fruits, especially in strawberries: A review. HortScience, 26, 10-14.

Mikko J. Anttonen. (2007). Evaluation of Means to increase the content of bioactive phenolic compounds in soft fruits. (Doctoral dissertation) University of Kuopio (Chapter 4).

Morrison, RT. (1997). Edema and principles of diuretic use. Med Clin North Am, 81(3), 689-704.

Mukherjee, P.K., Das, J., Saha, K., Pal, M. \& Saha, B.P. (1996). Diuretic activity of rhizome of Nelumbo nucifera Gaertn (Nymphacaceae). Phytotherapy Research, 10, 424-425.

Mullen, W., Lean, M.E. \& Crozier, A. (2002). Rapid characterization of anthocyanins in red raspberry fruit by high-performance liquid chromatography coupled to single quadrupole mass spectrometry. Journal of Chromatography A, 966, 63-70.

Murugesan, T., Manikandan, L., Suresh, K.B., Pal, M. \& Saha, B.P. (2000). Evaluation of diuretic potentials of J. suffruticosa Linn extracts in rats. Indian Journal of Pharmaceutical Sciences, 62, 150.

Oomah B.D., Ladet S., Godfrey D.V., Liang, J. \& Girard, B. (2000). Characteristics of raspberry (Rubus idaeus L.) seed oil. Food Chemistry, 69(2), 187-193.

Parsons, M. (2000). Raspberry leaf tablets and their effect on labor and birth outcomes. International Journal of Gynecology and Obstetrics, 70(3), 53-54(2).

Parsons, M., Simpson, M. \& Ponton, T. (1999). Raspberry leaf and its effect on labor: safety and efficacy. Aust Coll Midwives Inc J, 12(3), 20-25.

Patel, A.V., Rojas-Vera, J. \& Dacke, C.G. (2004). Therapeutic constituents and actions of Rubus species. Current Medicinal Chemistry, 11(11), 1501-1512.

Ryan, T., Wilkinson, J.M. \& Cavanagh, H.M. (2001). Antibacterial activity of raspberry cordial in vitro. Research in Veterinary Science, 71, 155-159.

Shiow Y.Wang, Chi-Tsun Chen \& Chien Y. Wang. (2009). The influence of light and maturity on fruit quality and flavonoid content of red raspberries. Food Chemistry, 112, 676-684.

Simpson, M., Parsons, M., Greenwood, J. \& Wade, K. (2001). Raspberry leaf in pregnancy: its safety and efficacy in labor. J Midwifery Women's Health, 46, 51-59.

Sripanidkulchai, B., Wongpanich, V., Laupattarakasem, P. \& Suwansaksari, J. (2001). Diuretic effects of selected Thai in digenous medicinal plants in rats. Journal of Ethnopharmacology, 75, 185-190.

Whitehouse, B. (1941). Frafarine: an inhibitor of uterine action. British Medical J, 2:370-371.

Table 1: Urine volume after the treatment with Rubus idaeus L. extract over a period of $4 \mathrm{~h}$

\begin{tabular}{|c|c|c|c|c|c|c|c|}
\hline \multirow{2}{*}{ Treatment } & \multirow{2}{*}{$\begin{array}{c}\text { Dose }^{1} \\
(/ \mathbf{k g ~ B W})\end{array}$} & \multicolumn{5}{|c|}{ Urine volume (ml/100g BW) } & \multirow{2}{*}{$\begin{array}{c}\text { Diuretics } \\
\text { Action }^{4}\end{array}$} \\
\hline & & $1 h^{2}$ & $2 \mathrm{~h}^{2}$ & $3 h^{2}$ & $4 h^{2}$ & Total $^{3}$ & \\
\hline Distilled Water & - & 0.76 & 0.26 & 0.21 & 0.07 & $1.30 \pm 0.19$ & 1 \\
\hline HCTZ & $10 \mathrm{mg}$ & $1.43 *$ & 0.08 & 0.61 & $0.34^{*}$ & $2.50 \pm 0.30 * *$ & 1.90 \\
\hline TM & $2 \mathrm{~g}$ & 0.73 & 0.11 & 0.36 & 0.10 & $1.30 \pm 0.29$ & 1.00 \\
\hline FM & $2 g$ & 0.83 & 0.32 & 0.03 & $0.44 *$ & $1.62 \pm 0.28$ & 1.25 \\
\hline $\mathrm{RM}$ & $2 \mathrm{~g}$ & 0.52 & 0.58 & $0.69^{*}$ & $0.54^{*}$ & $2.32 \pm 0.12^{* *}$ & 1.69 \\
\hline TW & $2 \mathrm{~g}$ & 0.79 & 0.21 & 0.19 & 0.16 & $1.34 \pm 0.27$ & 1.03 \\
\hline FW & $2 \mathrm{~g}$ & 1.04 & 0.28 & 0.21 & 0.12 & $1.64 \pm 0.43$ & 1.26 \\
\hline RW & $2 g$ & 0.66 & 0.23 & 0.16 & 0.30 & $1.35 \pm 0.23$ & 1.04 \\
\hline
\end{tabular}

${ }^{1} \mathrm{mg} / \mathrm{kg}$ of hydrochlorothiazide and $\mathrm{g}$ of dried plant before extracted per $\mathrm{kg}$.

${ }^{2}$ Each value represents the mean.

${ }^{3}$ Each value represents the mean \pm S.E.M.

${ }^{4}$ Diuretics action $=($ total urinary excretion of treated group $(4 \mathrm{~h})) /($ total urinary excretion of control group $(4 \mathrm{~h}))$. 
${ }^{*} \mathrm{P}<0.05$ compared with the control group, $* * \mathrm{P}<0.01$ compared with the control group.

Table 2. Sodium and potassium excretion observed from the urine of experimental rats

\begin{tabular}{|c|c|c|c|c|c|}
\hline \multirow{2}{*}{ Treatment } & $\begin{array}{c}\text { Dose } \\
\text { (mg/kg BW) }\end{array}$ & \multicolumn{4}{|c|}{ Na $^{+}(\mathbf{m m o l} / \mathbf{L})$} \\
\hline & & $1 \mathrm{~h}$ & $2 \mathrm{~h}$ & $3 \mathrm{~h}$ & $4 \mathrm{~h}$ \\
\hline Control & - & $64.42 \pm 12.56$ & $115.21 \pm 10.99$ & $105.09 \pm 15.91$ & $143.32 \pm 18.41$ \\
\hline HCTZ & 10 & $106.45 \pm 19.75$ & $128.70 \pm 17.99^{*}$ & $180.98 \pm 16.48^{* *}$ & $139.42 \pm 18.57$ \\
\hline RIEA & 200 & $87.12 \pm 18.85^{*}$ & $110.49 \pm 6.92$ & $128.84 \pm 13.66^{*}$ & $110.23 \pm 1.39$ \\
\hline & & & \multicolumn{3}{|c|}{$\mathrm{K}^{+}(\mathrm{mmol} / \mathrm{L})$} \\
\hline Control & - & $56.88 \pm 5.93$ & $110.49 \pm 6.92$ & $97.09 \pm 7.72$ & $106.37 \pm 10.69$ \\
\hline HCTZ & 10 & $67.30 \pm 17.38$ & $114.14 \_12.49^{* *}$ & $124.92 \pm 18.21 *$ & $142.09 \pm 14.56^{*}$ \\
\hline RIEA & 200 & $33.34 \pm 5.86^{* *}$ & $61.11 \pm 9.10$ & $51.80 \pm 9.37^{* *}$ & $72.58 \pm 2.09^{*}$ \\
\hline
\end{tabular}

Each value represents the Mean \pm S.E.M

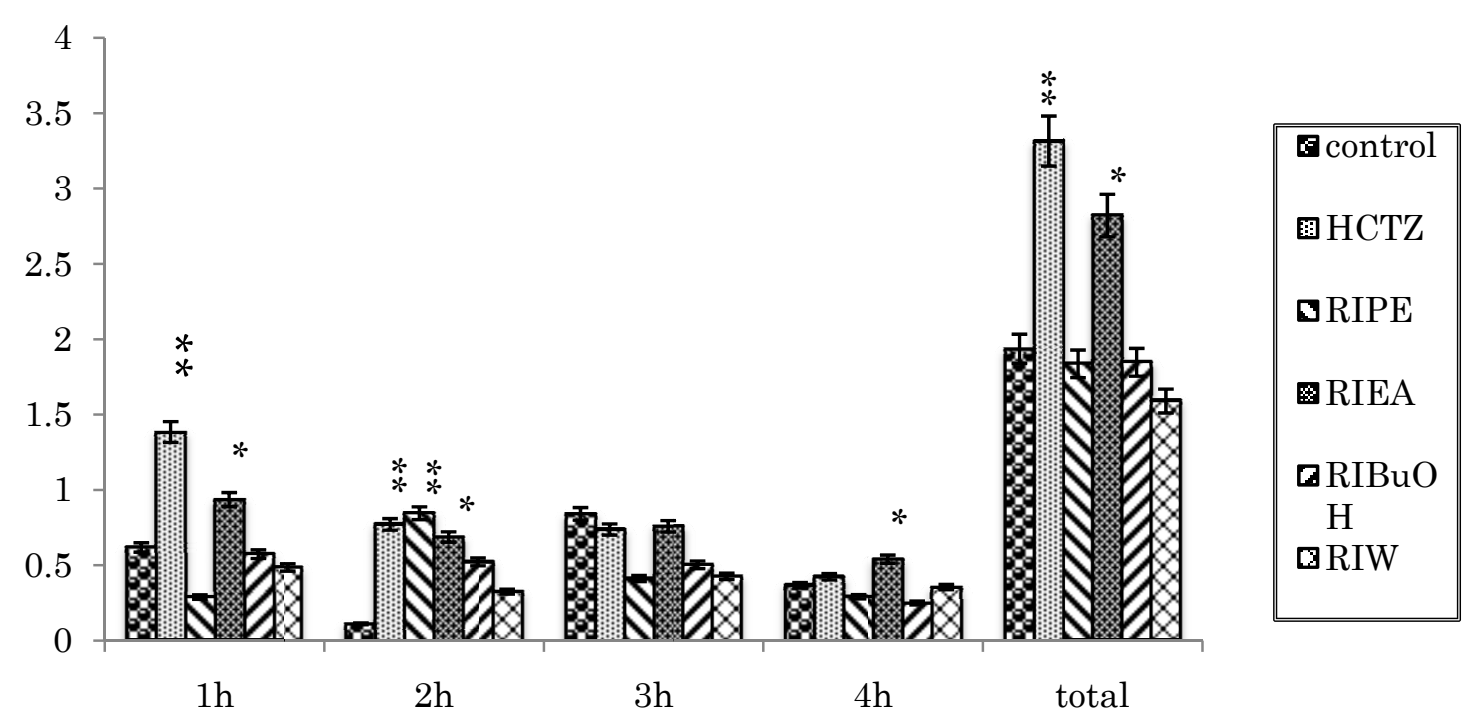

Figure 1. Urine volume produced by four fractions of methanol extracts 